This Section of Epidemiology and Psychiatric Sciences appears in each issue of the Journal and is dedicated to all forms of creative production born of an intimate and individual urge, often secretive, unbound from the conventional art system rules. Through short descriptions of the Outsider art work of prominent artists and new protagonists often hosted in community mental health services, this Section intends to investigate the latest developments of the contemporary art scene, where the distances between the edge and the centre are becoming more and more vague.

Carole Tansella, Section Editor

\title{
Mariapaola Martinelli's ultra flat space
}

\section{Tansella}

Department of Time, Space, Image, Society, University of Verona, Verona, Italy

Received 14 November 2013; Accepted 14 November 2013; First published online 13 December 2013

Key words: Italian contemporary art, Mariapaola Martinelli, Outsider art.
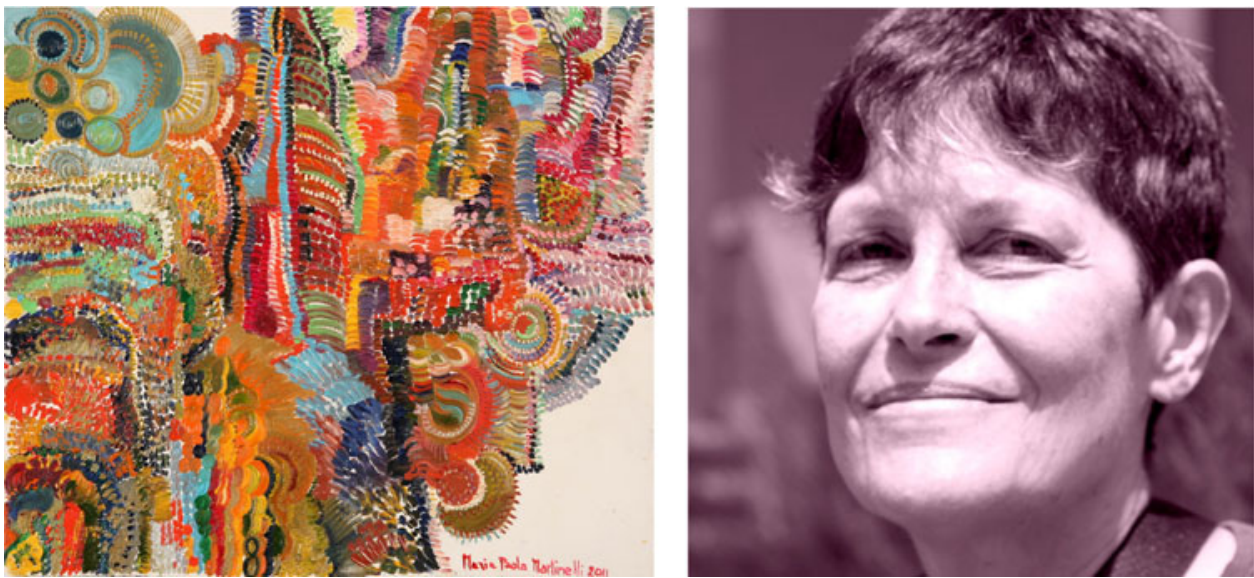

On the left: Mariapaola Martinelli: Untitled, Oil on canvas, (2011), $46 \times 52 \mathrm{~cm}$, Collection Atelier OBA - Omino Bianco Azzurro. On the right: Photo of the artist.

This Epidemiology and Psychiatric Sciences (EPS) Section was created under the premise that, what is commonly called Contemporary Art, is only one of the sides of a world composed of a myriad of facets and of these,

Address for correspondence: Dr Carole Tansella, Department of Time, Space, Image, Society, University of Verona, Via San Francesco 22, 37129 Verona, Italy.

(Emails: carole.tansella@gmail.com; carole.tansella@univr.it) some are easier on the eyes than others. Nowadays it might not be still appropriate to make distinctions between modern artists and outsider artists, albeit in an equivalence relation (Tuchman \& Eliel, 1992), and indeed we think that in the field of aesthetics, the precepts of geometry are overthrown and that 'parallel visions' coincide more often than we like to imagine. The artistic career of Carlo Zinelli is an embodiment of just this boundary spanning (Tansella, 2013). It is 
however, undeniable that the crossing of margins from one territory to another is a long and uncertain path that leads to the surrender of a piece of ones history in favour of a new identity that no longer permits explicit connections to the sphere of Mental Health.

Mariapaola Martinelli is a prolific, experimental artist who is now working at the interface between official art and so-called outsider art. She was born in Ala, a small village in the province of Trento, Italy at the foot of the Dolomites, in 1948. The eldest of three sisters, she completed her studies in Verona specialising in foreign languages. In 1990, she began to paint and attended for the Academy of Fine Arts of Verona for 1 year.

Since 2008 Martinelli has been painting regularly at the OBA - Omino Bianco Azzurro Atelier, located in the Mental Health Center in South Verona, led by the artist Igor Novelli. The OBA atelier is a creative space where about ten patients, men and women, attend with varying levels of participation. Unlike the centres of creative expression usually housed in mental health centres, OBA works free from strictly therapeutic purposes and supports the pursuit and exploration of the inventive sphere of each individual. As in the classical tradition of outsider art, all OBA artists are self-taught and are genuinely inexperienced, even disinterested in the mechanisms that regulate the art world (Tansella, 2012).

In this article I take into consideration the most fortunate creative period of Martinelli, constituted by the oils on paper and sculptures of her latest creations, which achieve a stylistic synthesis based on a model of spatial organisation set up on the accumulation of homogeneous elements. In her oil paintings, we see the elegance of calligraphic lines. Viewers can lose themselves in the succession of waves and curls adorning her paintings, departing, as they do, from the conventions of objective representation in Western culture. Small, firm and forthright touches produce the vortices, the corymbs and the clusters from the unbridled chromaticism of her painting, which follow each other relentlessly in an ornamental system that brings to mind the bulimic surfaces of Gustav Klimt. Martinelli, emancipated from the weight of the allegory that burdened the Viennese artist, zips joyfully accumulating two-dimensional elements and designs, without lights and without shadows, a space where the figures float on a surface without density. One's gaze moves along these light and precise signs, captured by the promise of pleasure, until losing balance in dizzying gaudy arabesques.

In the pair of skyscrapers, Martinelli presents a sculptural form moulded from hundreds of small pharmaceutical cartons stacked to shape two towers as tall as the artist. It is difficult not to think of the multinational pharmaceutical industry, which thrives at the expense of ill individuals, in their effort to maintain their health. The same theme is evident at the end of the 90s in the work of British artist Damien Hirst in his work, The Fragile Truth, which presents a stifled and lifeless cabinet full of pharmaceutical cartons in meticulous order. Martinelli's towers are the latest and transgressive creations of this narrative: they do not attempt to freeze behind a glass that filters one's fears, rather they invade the environment and forces one to rethink the common surrounding space (Tansella, 2012).

\section{References}

Tansella C (2012). Authentic visions. In Autentiche Visioni. Verona e l'Arte Irregolare da Carlo Zinelli a Oggi, Exhibition Catalogue, 9 November 2012-27 January 2013, Grafiche Aurora: Verona.

Tansella C (2013). The seminal work of Carlo Zinelli. Epidemiology and Psychiatric Sciences 22, 15-16.

Tuchman M, Eliel CS (1992). Parallel Visions. Modern Artists and Outsider Art. Princeton University Press: Princeton. 